\title{
Beam forming for a Laser Based Auto-stereoscopic Multi-Viewer Display
}

Hadi Baghsiahi, David R. Selviah, Eero Willman, F. Anibal Fernández, and Sally E. Day

h.baghsiahi@ee.ucl.ac.uk, d.selviah@ee.ucl.ac.uk

Dept. of Electronic and Electrical Engineering, University College London (UCL), London, UK

Kishore V. C., Erdem Erden and Hakan Urey

Dept. of Electrical Engineering, Koç University. Istanbul, Turkey

Phil. A. Surman

Imaging \& Displays Research Group, De Montfort University, Leicester, United Kingdom 


\section{Outline}

- Introduction: Laser-based Multi-user Multi-modal 3D Display

- Light engine (illumination)

- Transfer screen

- Head tracker

- Requirements of the HELIUM3D display system

- Laser-based display, advantages and disadvantages

- Rear projected display with horizontal scanning.

- Experiments and results

- Lasers characterization

- Speckle suppression due to:

- Number of diffusers

- Number of independent emitters

- Material stability in exposing high optical power

- Laser beam homogenizing and beam shaping

- Conclusions 


\section{HELIUM3D System}

High Effficiency Laser-based Multi-usser Multi-modal 3D Display

The HELIUM3D display consists of 3 main subsystems:

1. Light Engine

Produces horizontally scanned columns of image frames.

2. Head Tracker Determines viewer eye positions.

3. Transfer Screen Relays the scanned image columns to viewer locations

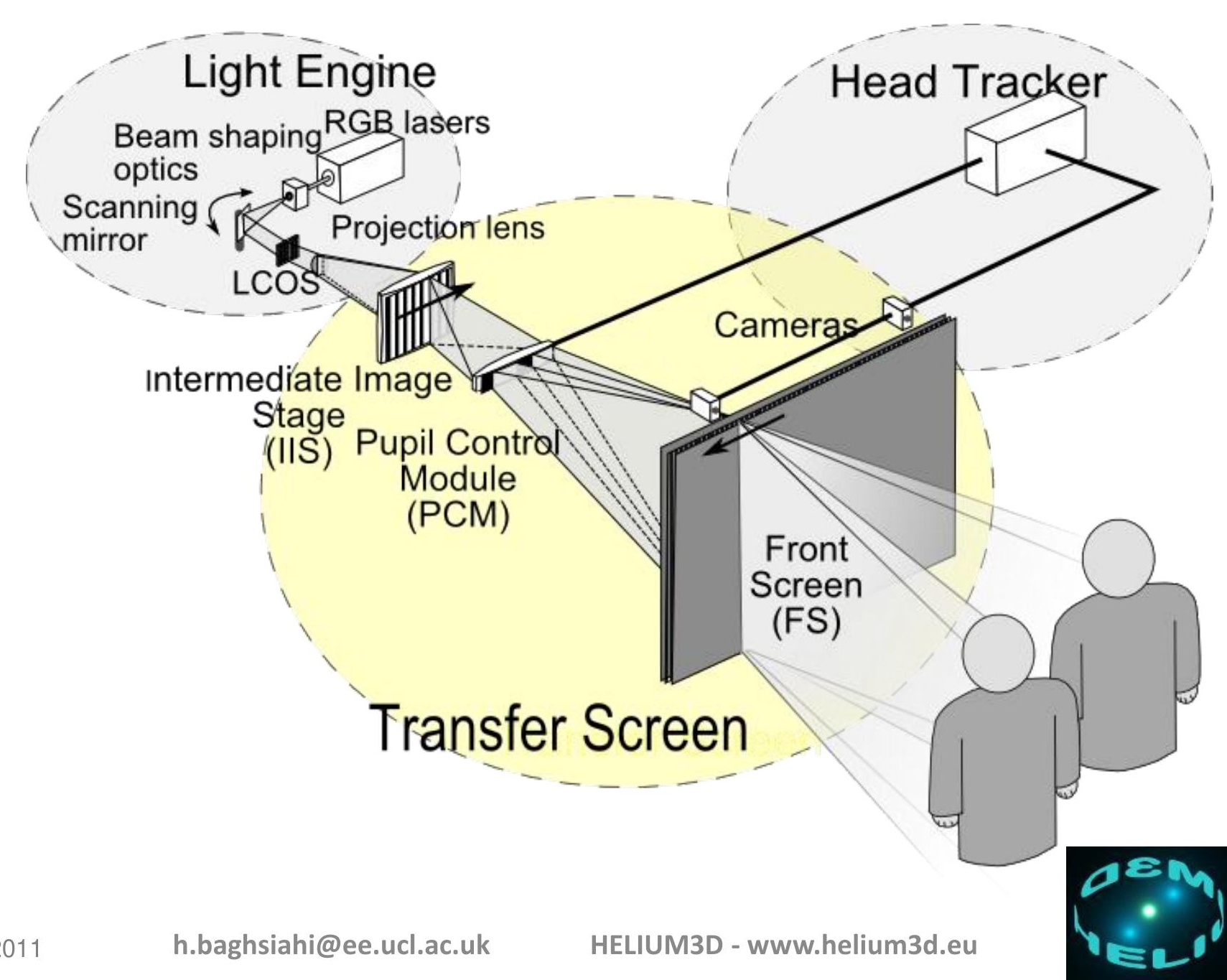


Beam shaping

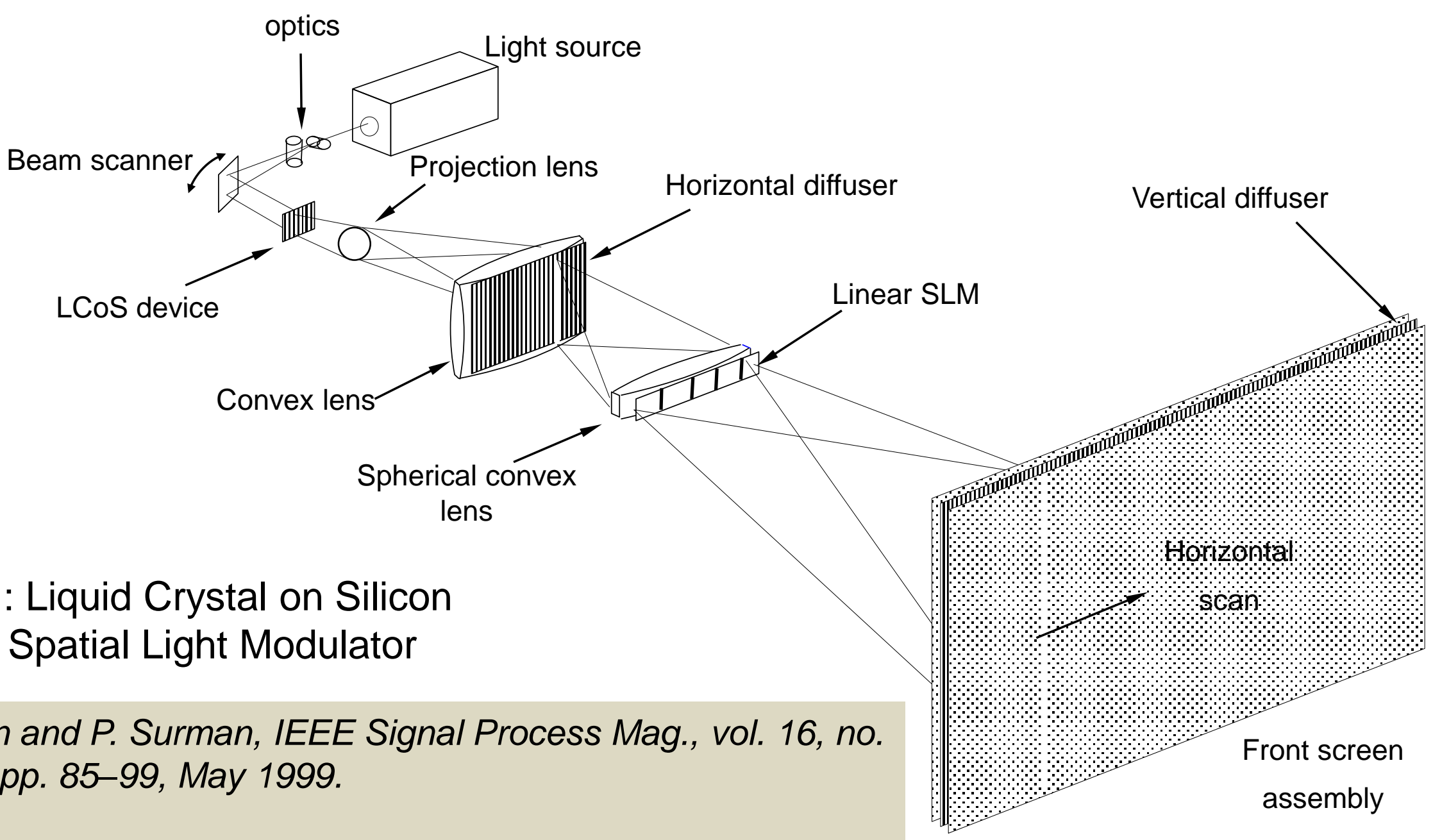

E. Willman, et al. "The Optics of an Auto-stereoscopic Multiview Display" 2010 SID International Symposium Digest of Technical Papers. Society for Information Display, (16.4).

LCoS : Liquid Crystal on Silicon SLM : Spatial Light Modulator

Sexton and P. Surman, IEEE Signal Process Mag., vol. 16, no. 3, pp. 85-99, May 1999. 


\section{HELIUM3D special requirements:}

- A narrow homogenized beam to scan across the LCoS to illuminate the image.

- Scanning beam is required so that the whole exit pupil volume can be accessed.

- Output of the light source must be shaped to give a narrow light line with low étendue.

- High power light sources are required to provide enough optical energy.

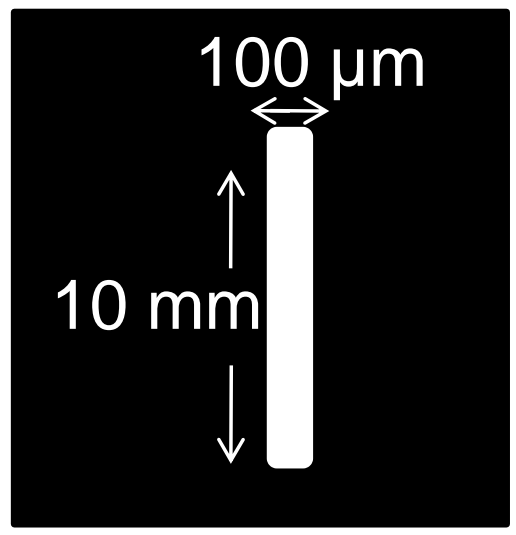




\section{AIVCL \\ dmu.ac.uk DE MONTFORT

\section{RGB Laser based Light Engine}

Advantages:

- High optical power

- Large colour gamut

- Low étendue

Disadvantages:

- Speckle problem

- Power density

- Safety issues

- Cost
Laser Selection: :

- Spectral line-width and Speckle problem

- Optical power

- Beam quality

- Polarization ratio

- Size of the laser

- Cost 
AJVAL

\section{Light sources for the light engine}

2 laser arrays, green and blue (NECSEL), and one red laser bar

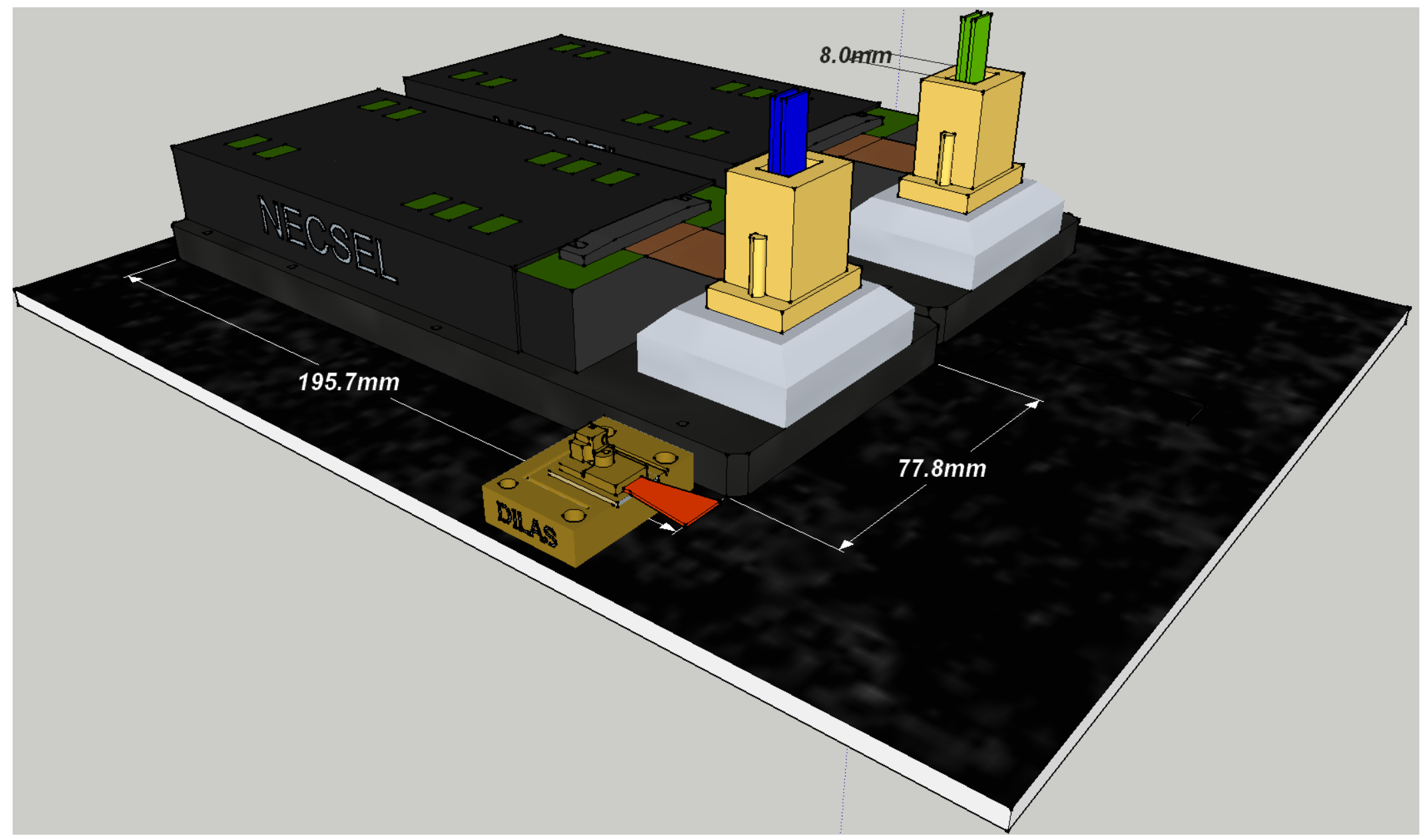




\section{Laser characterization}

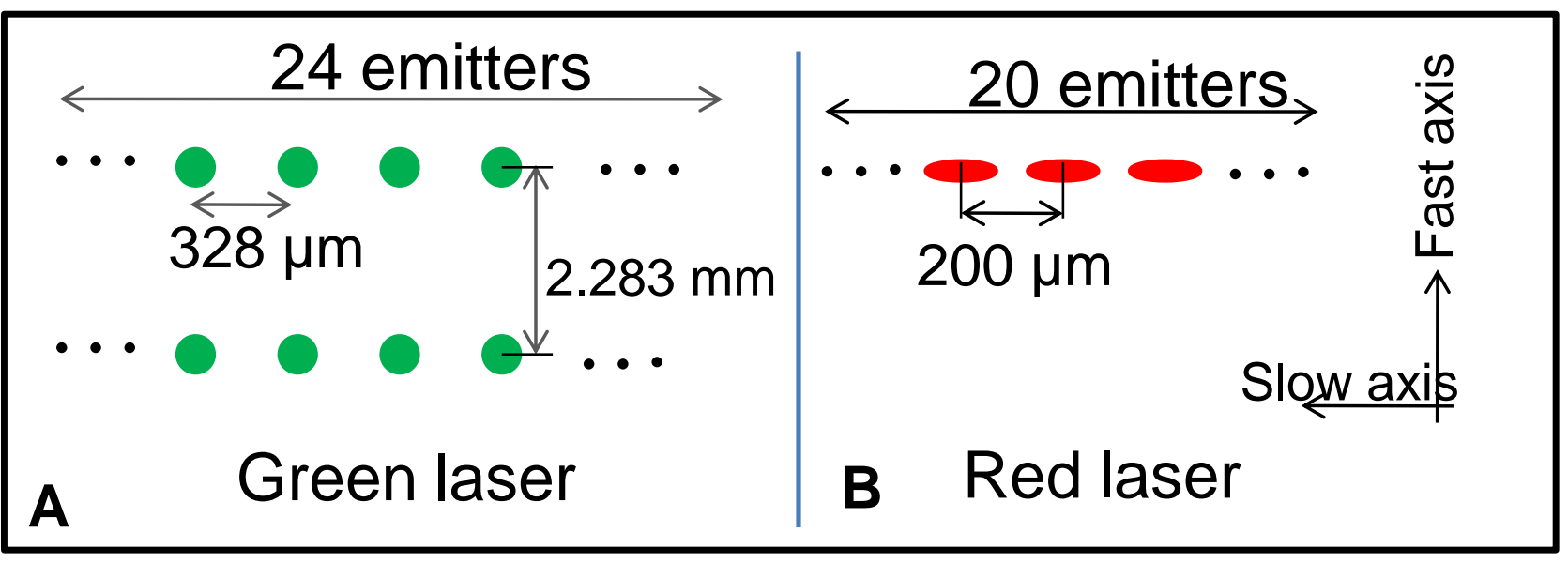

A: Emitter spacing of NECSEL (48 emitters in two rows)

B:Emitter spacing of red diode laser (20 emitters in one row)

C: Divergence of one emitter (top row)

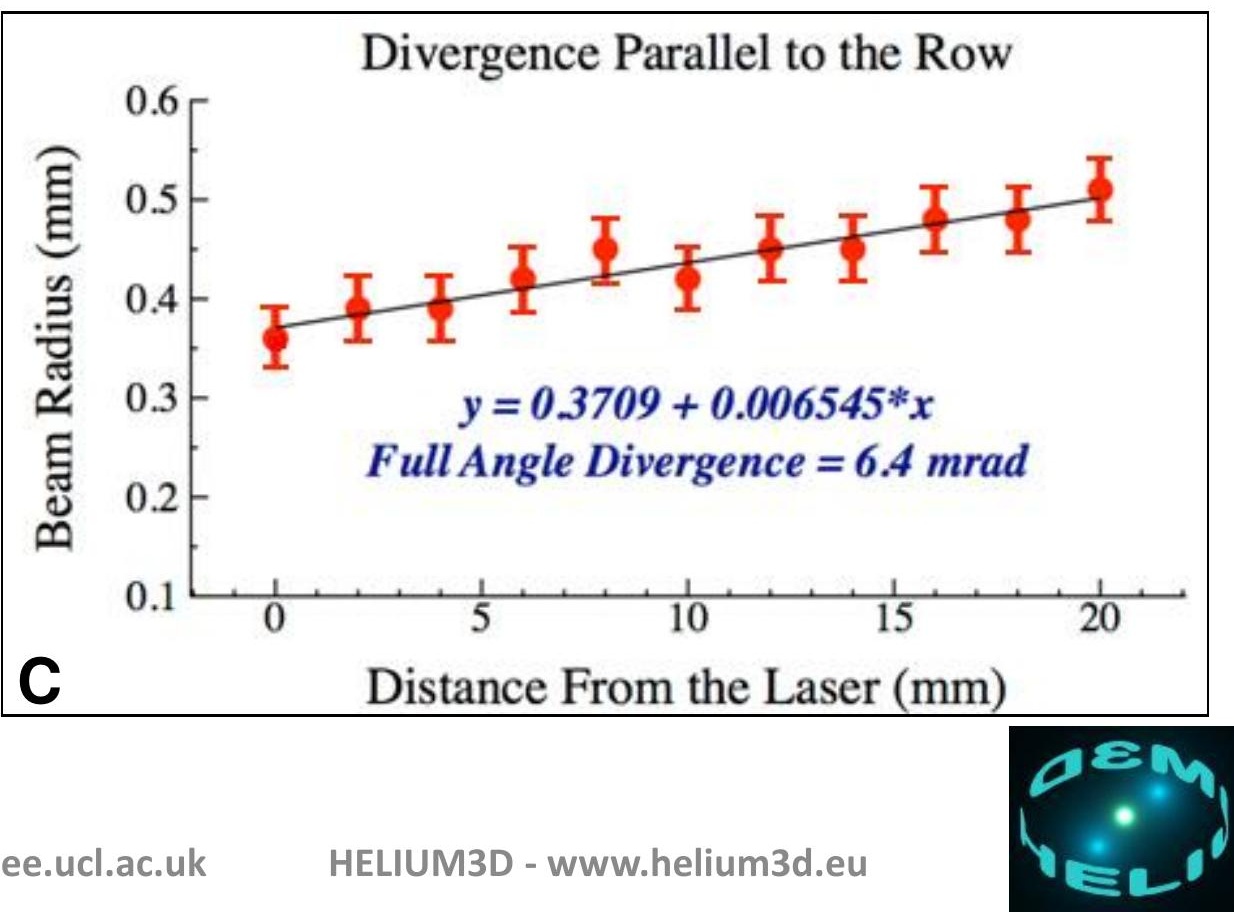




\section{Light Engine}

The light engine produces time-multiplexed scanned views of the displayed image content.

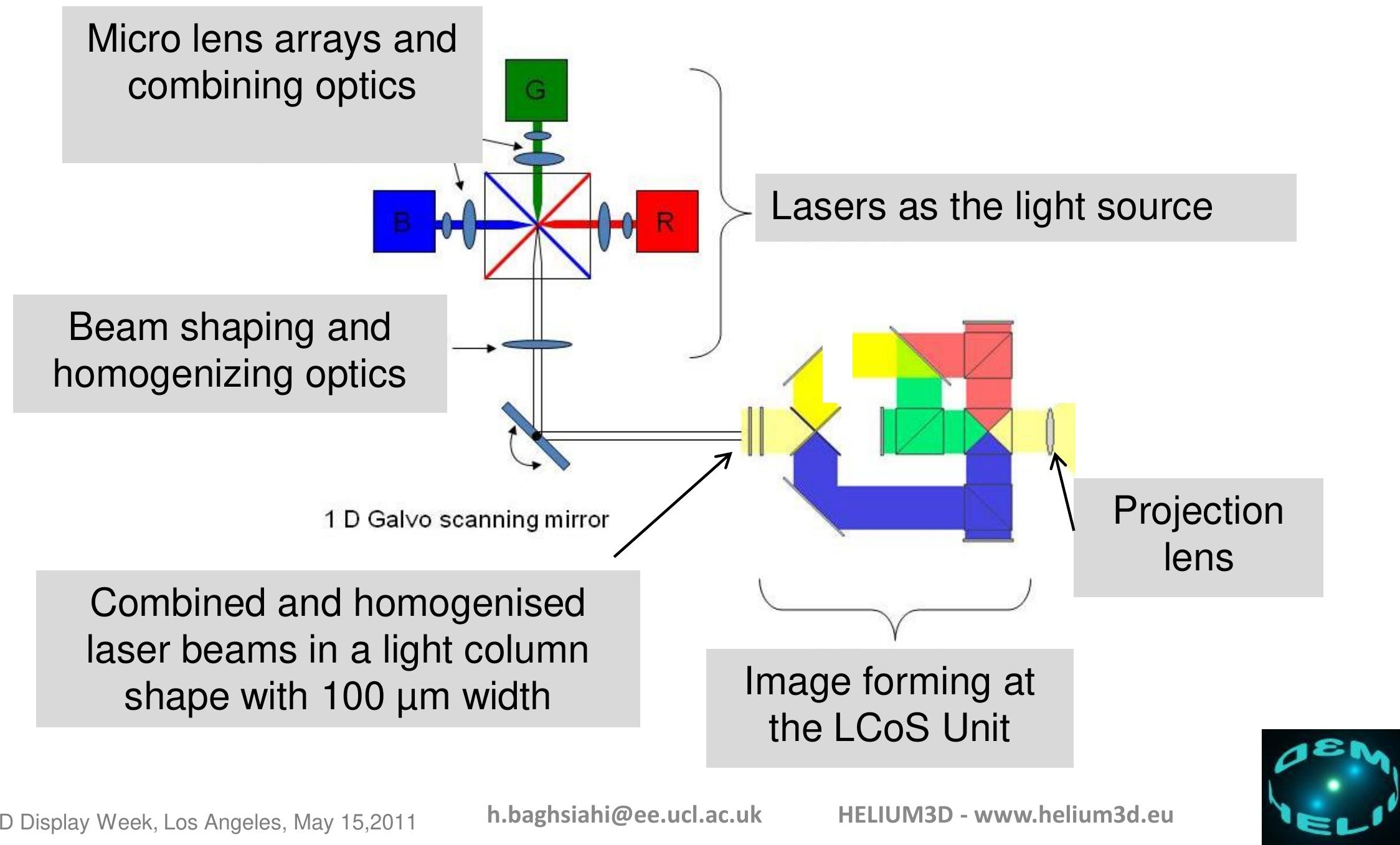




\section{Speckle contrast measurements}

Speckle is a fine scale granular interference pattern, quantified by the speckle contrast which is defined as:

Speckle contrast $=\frac{\text { Standard deviation }}{\text { Mean value }}$

1. Speckle suppression due to the diffusers

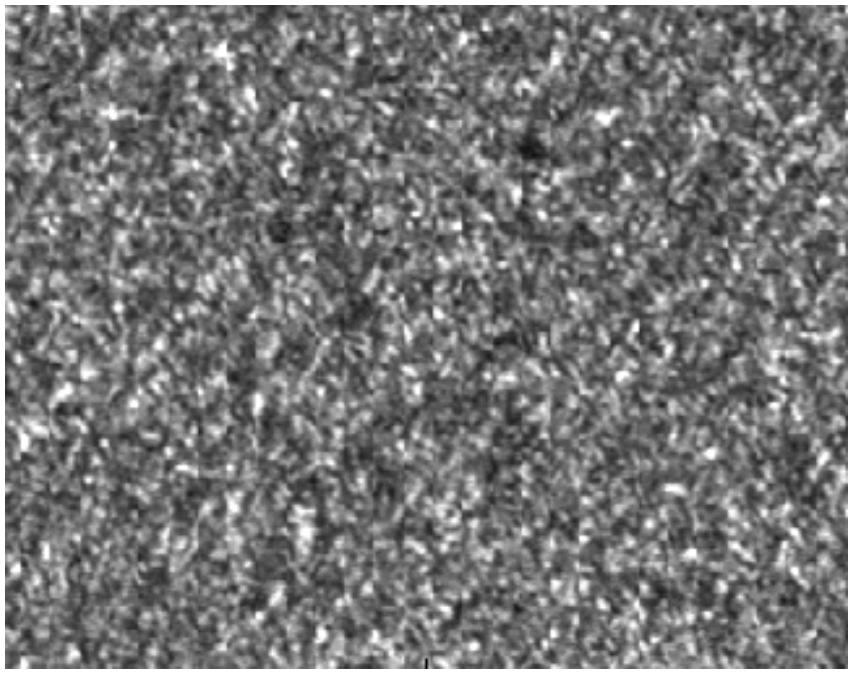

2. Speckle suppression due to the multiple sources. 


\section{Speckle contrast measurements with diffusers}

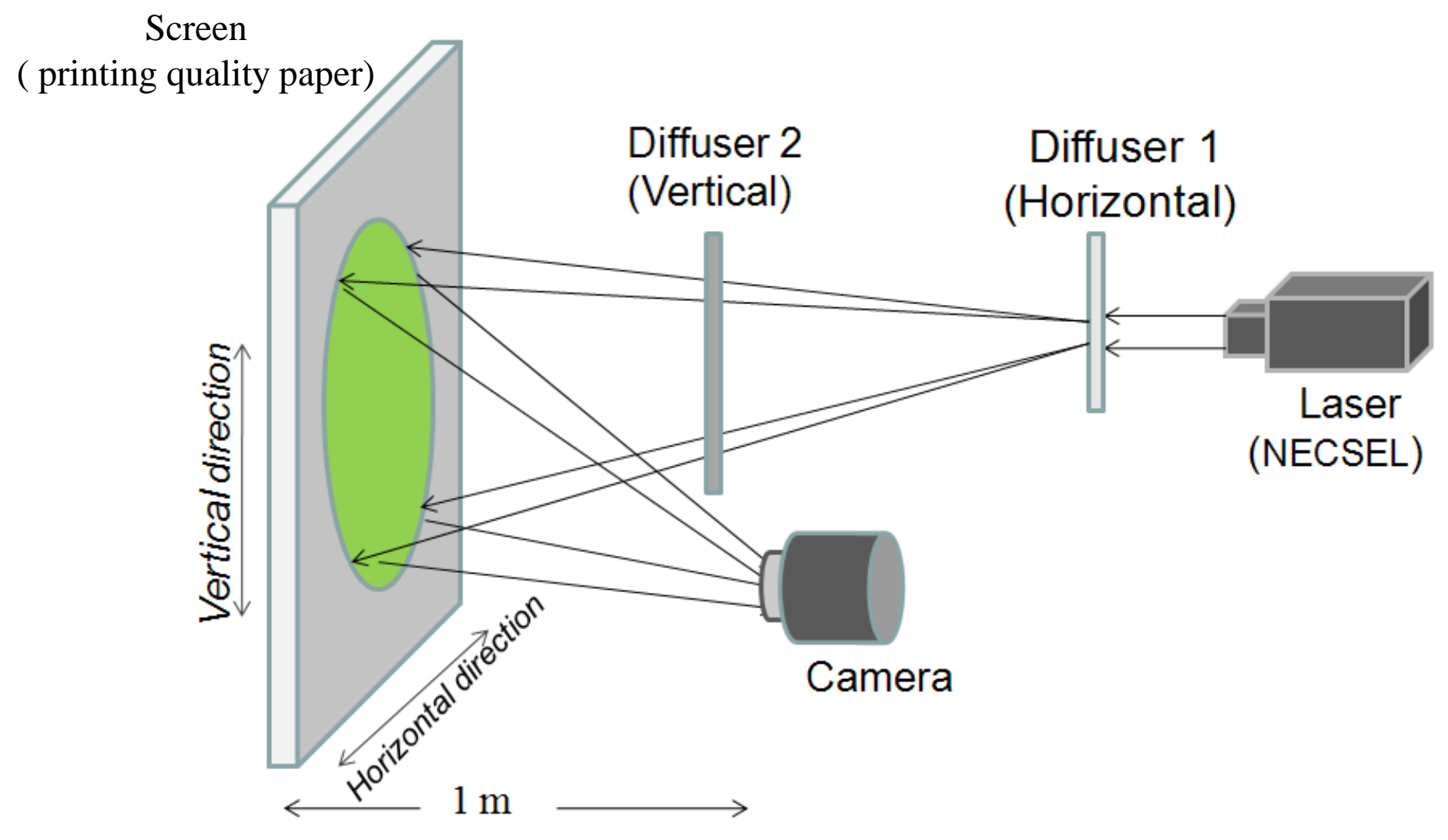

Schematic diagram of the experiment of measuring the speckle contrast. (The diffusers and the space between them is the same as the real system) 


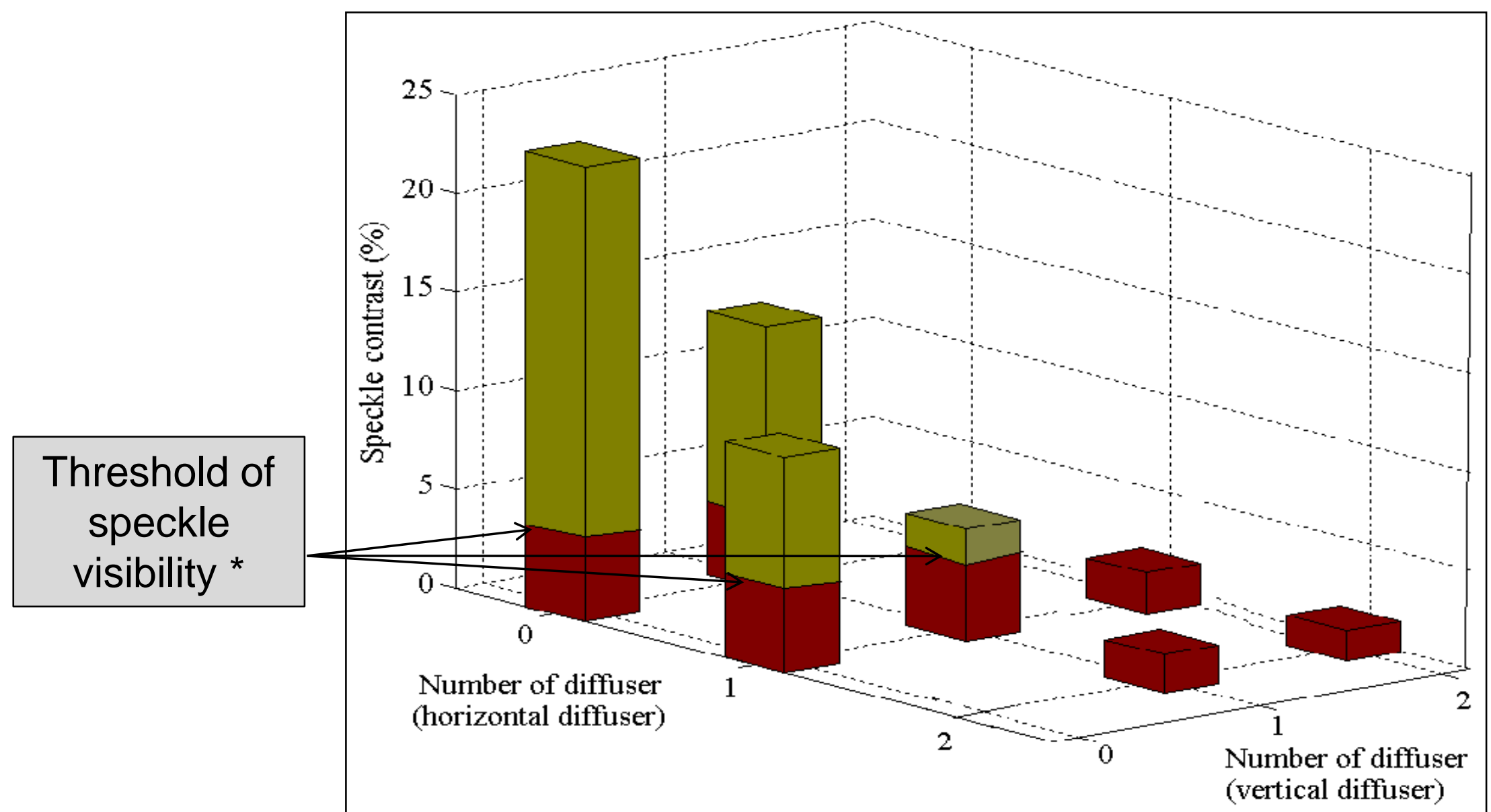

Speckle contrast for various numbers and orientations of diffusers.

Each diffuser diverges the light by $30 \quad 5$ (523 mrad). Only 10 emitters are operating to reduce the power density at the diffusers position. 


\section{Speckle contrast variation with number of emitters}

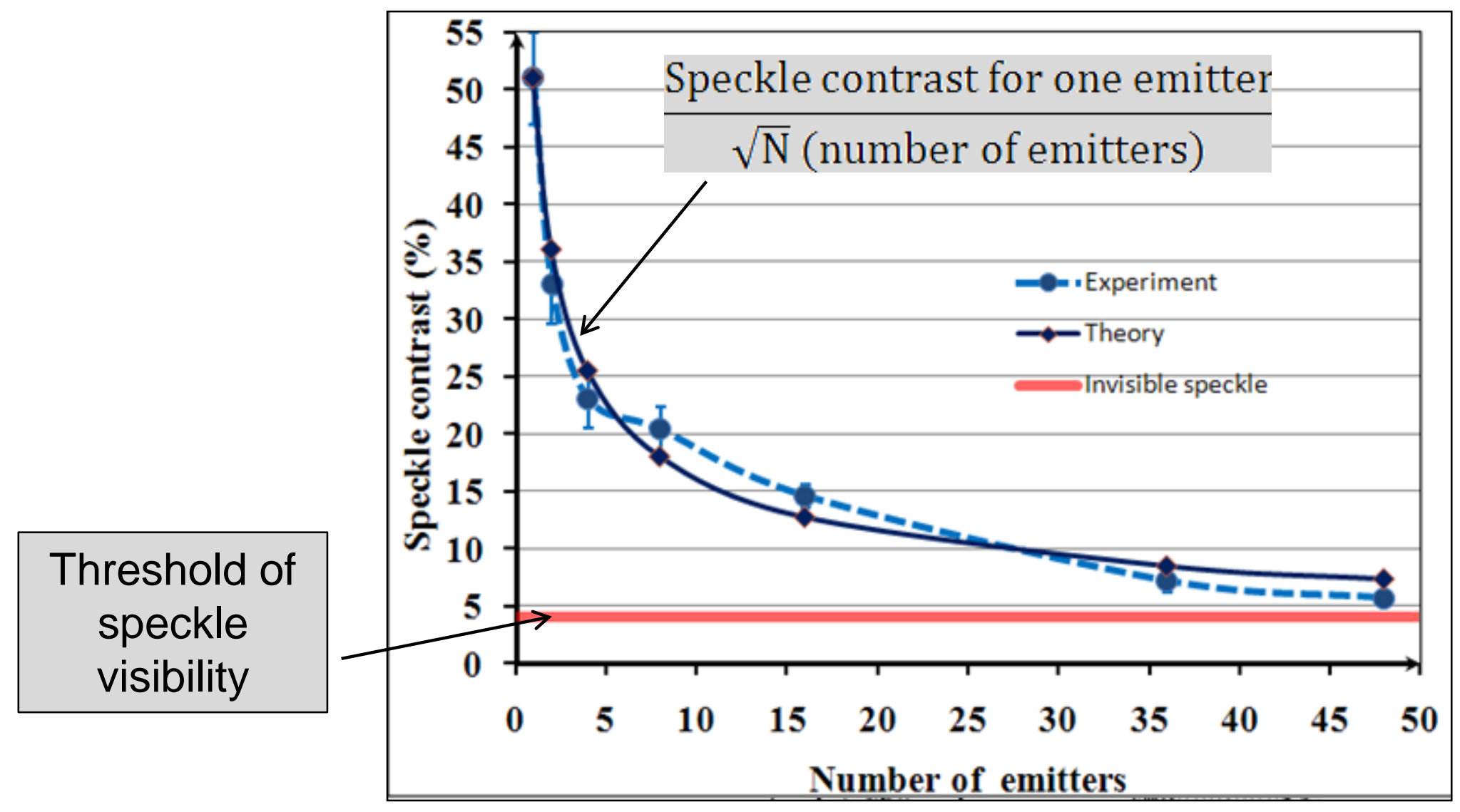

Speckle contrast obtained as a function of number of independent emitters. Any speckle pattern with a contrast below the red line $(<4 \%)$ is imperceptible 


\section{High optical power density - material dependence}

The microlenses used for beam forming are made from three layers

- The sample was exposed directly to a green NECSEL laser for 2.5 hours.

- The power density was $0.7 \times 10^{7} \mathrm{~W} / \mathrm{m}^{2}\left(0.7 \times 10^{3} \mathrm{~W} / \mathrm{cm}^{2}\right)$ at the surface of the sample

\begin{tabular}{|l|ll|l|ll|}
\hline Layer & \multicolumn{2}{|c|}{$\begin{array}{c}\text { Thickness } \\
(\boldsymbol{\mu m})\end{array}$} & Material & \multicolumn{2}{|c|}{$\begin{array}{c}\text { Refractive } \\
\text { index }\end{array}$} \\
\hline Layer 1 & 4000 & 10 & PMMA & 1.51 & 0.01 \\
\hline Layer 2 & 50 & 5 & Adhesive & 1.49 & 0.02 \\
\hline Layer 3 & 250 & 10 & Plexiglass & 1.49 & 0.01 \\
\hline
\end{tabular}

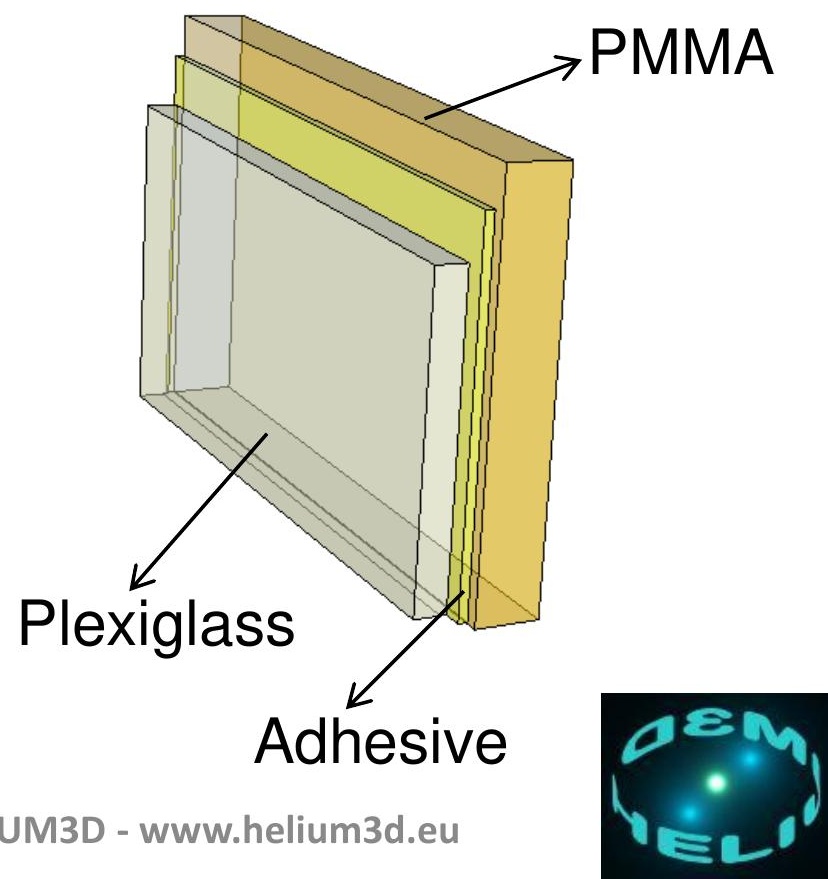




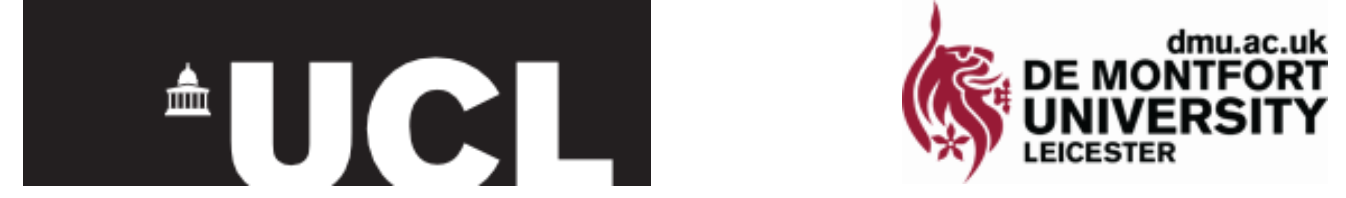

\section{High optical power density - material dependence}

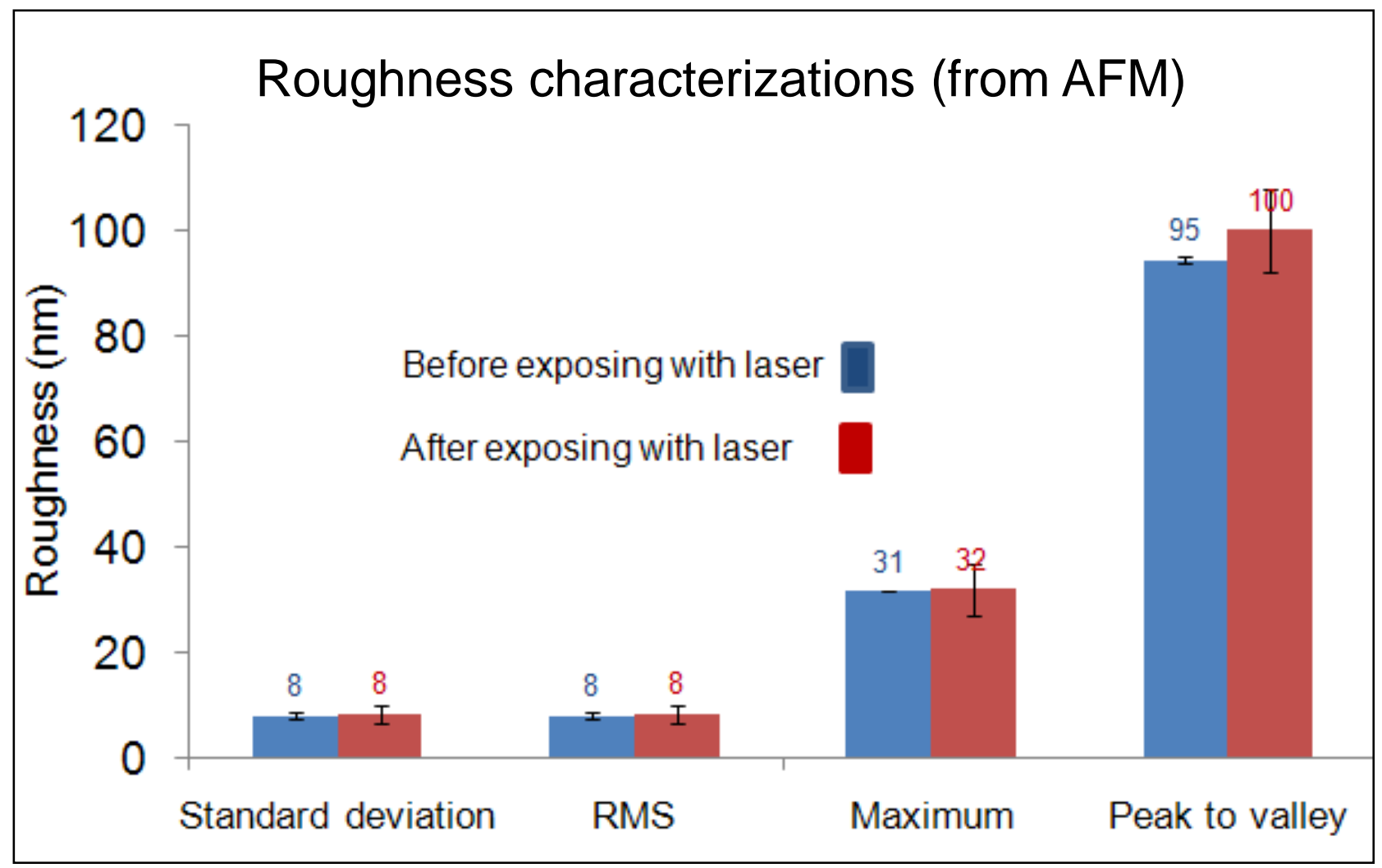

A comparison of the roughness for the polymer (PMMA) before

(blue) and after (red) exposing with the high power laser. 
AIJCL

6. KOC UNIVERSTIY

High optical power density - material dependence

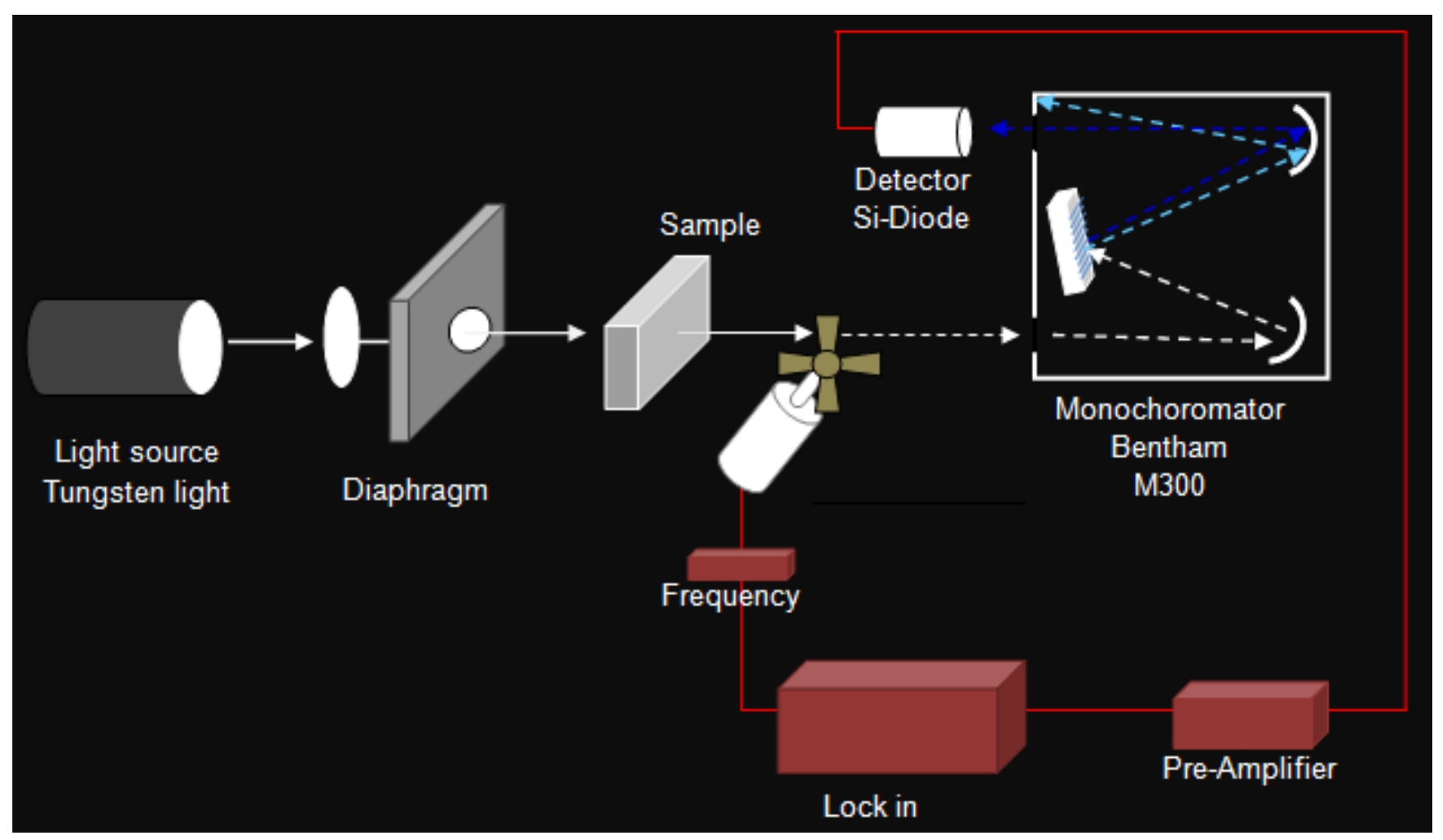

Experiment configuration of the measurement of transmitted spectrum of the sample 


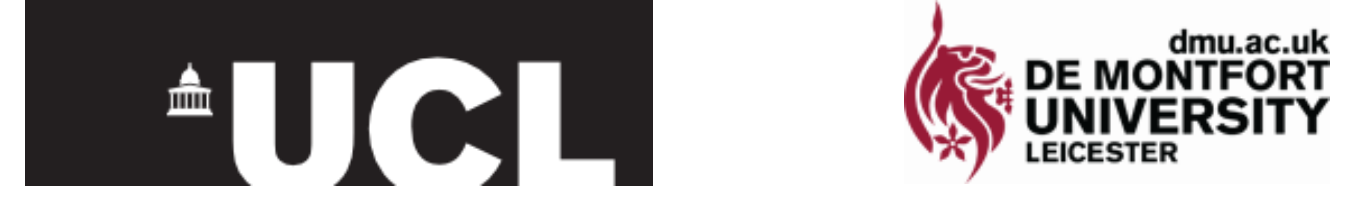

\section{High optical power density - material dependence}

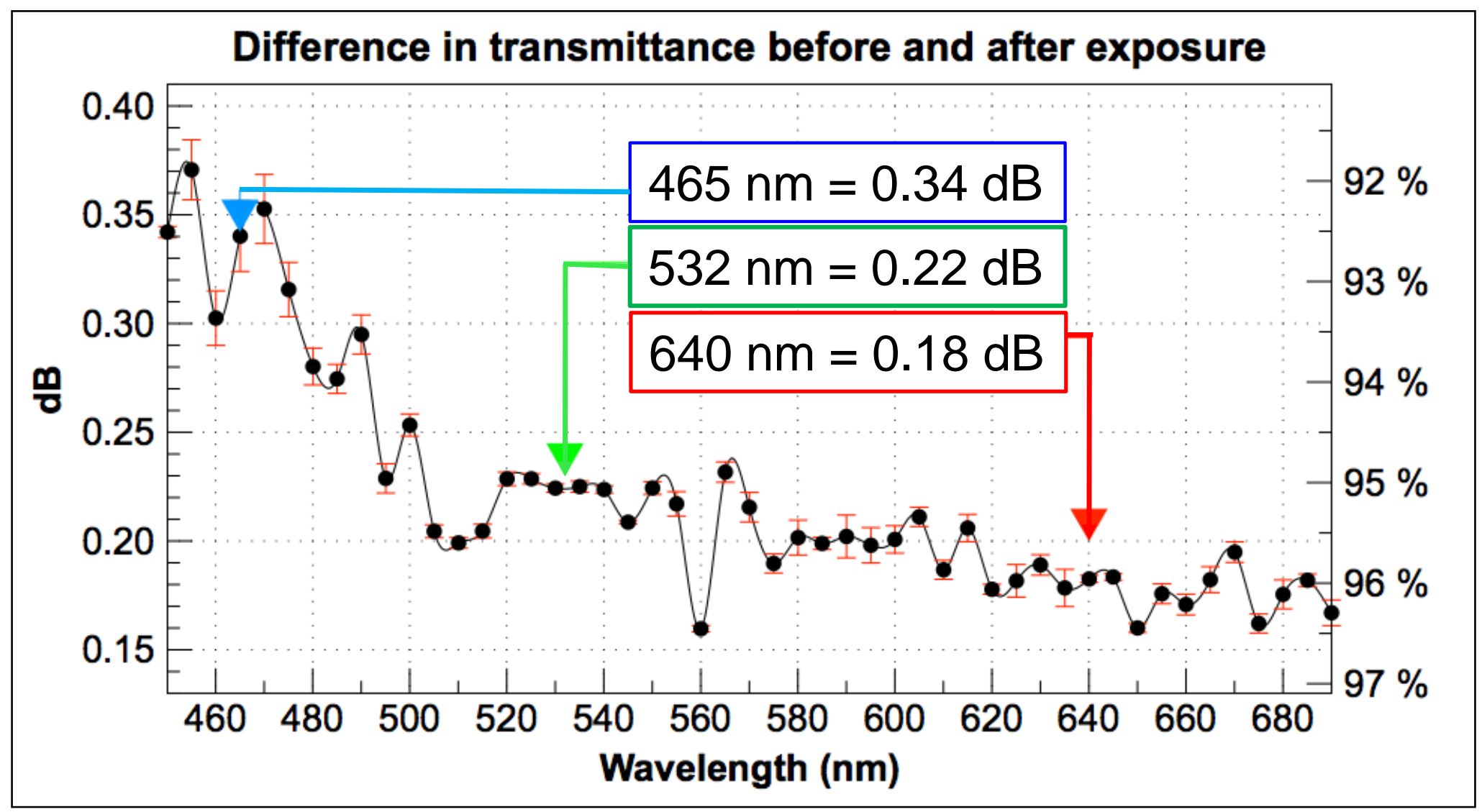

Difference in spectral transmission before and after exposure 


\section{Beam shaping and homogenizing}

The light engine must produce a homogenised light line to scan on the LCoS device.

There are different methods to homogenize the beam:

- Using microlens array in free space approach

- Emitters are arranged in two rows

- Each emitter is a coherent Gaussian beam

- Interference pattern applies a non-uniformity on the line

- Using two rows of emitters will require complex design.

- Using wave

- Optical

- All the $\epsilon$

- No inter

- Safe an

- Can be

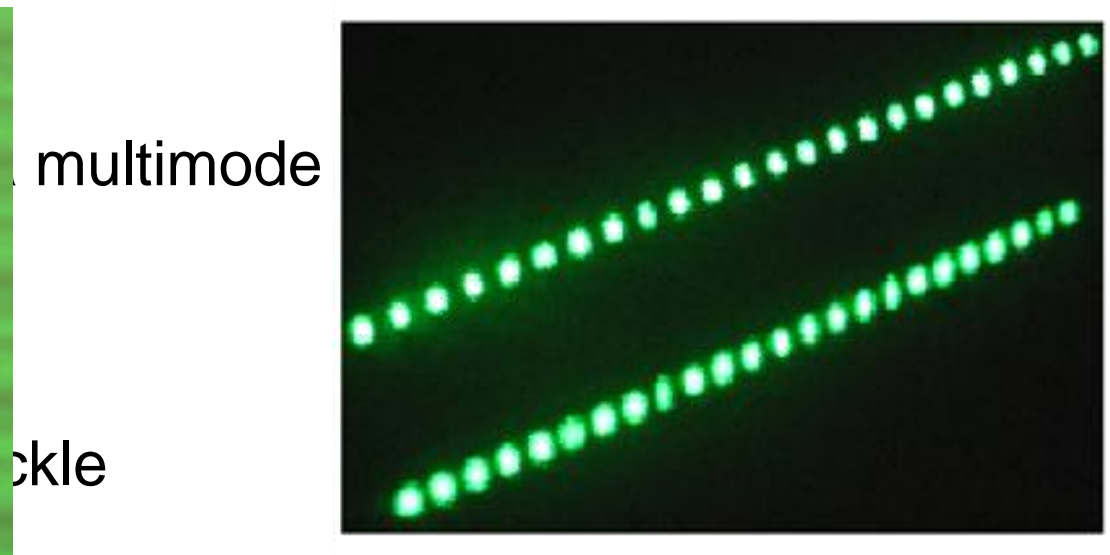


АIVCL

\section{Beam shaping and homogenizing}

- The output of the laser are combined by means of dichroic mirror

- The combined beams are focused into the multimode fibre

- Multimode optical fibre is used to homogenise the laser light

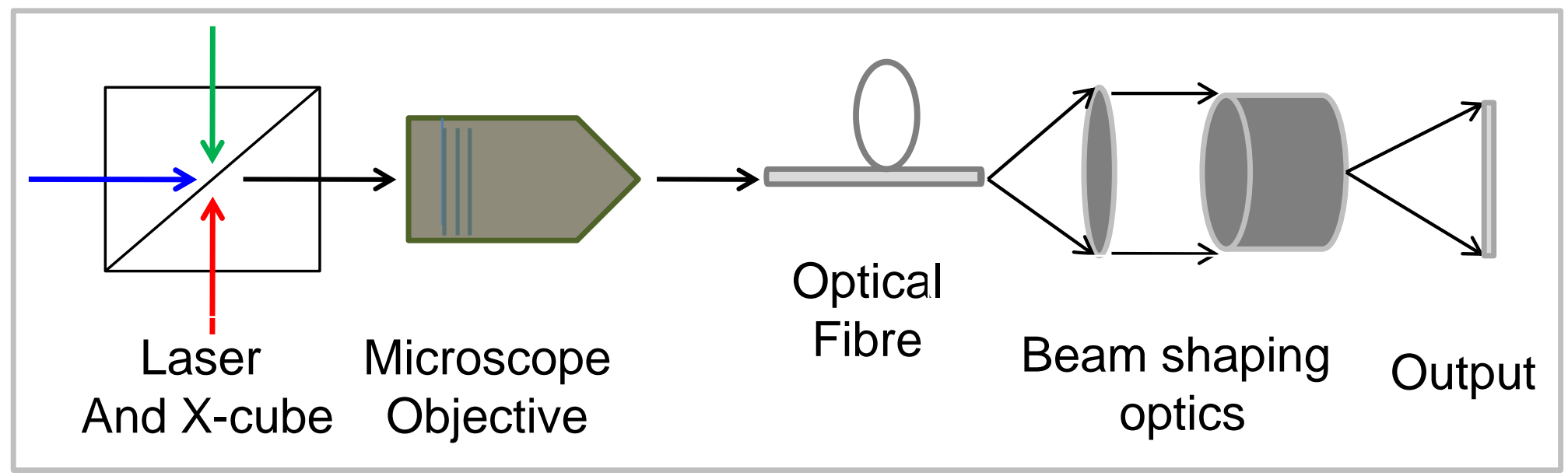

Experiment set up for laser-fibre coupling 
Maximum $=161$

Minimum $=137$

Standard deviation $=5.7$

Uniformity $=85 \%$
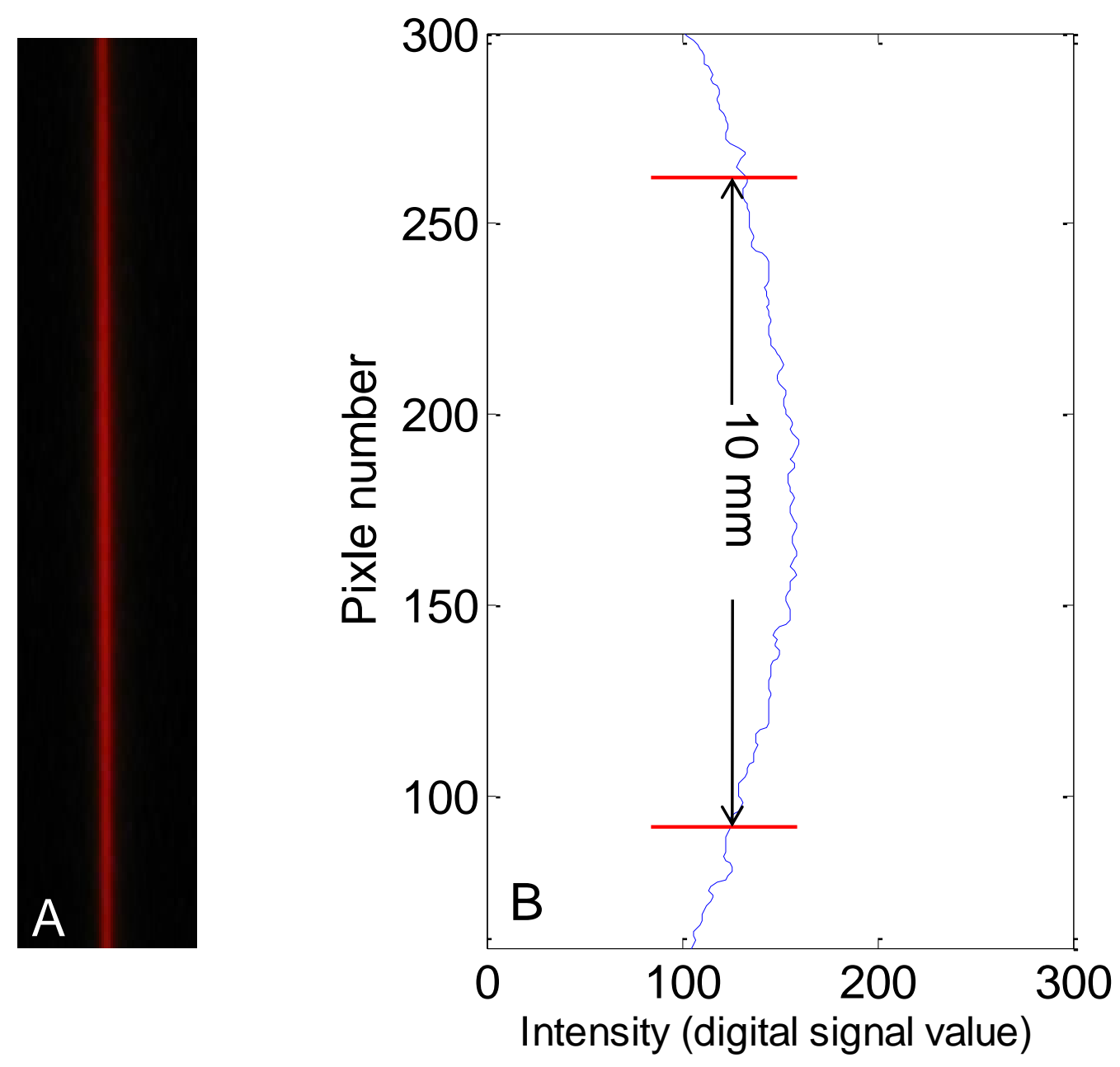

The shape of the beam after homogenizing and shaping by using optical fibre.

A: picture of the line

$B:$ The profile of the intensity across the line 


\section{Conclusions}

- Multi-emitter lasers were characterized and used as the light source.

- Speckle was reduced by using diffusers and multi-emitter lasers.

- Both diffusers and multi-emitter lasers are needed to reduce the speckle contrast to below the threshold of human perception.

- Optical fibre is used to homogenize the laser beam. ( $85 \%$ uniformity)

- Using optical fibre enables efficient use of the laser power and provides high flexibility to the system.

- Multimode optical fibre can be adopted in other display systems for homogenization and to reduce the system size. 


\section{Thanks for your attention}

www.helium3d.eu

\section{h.baghsiahi@ee.ucl.ac.uk}

- The HELIUM3D project is funded from the European Union Framework 7 (Grant 215280).

- We would also like to thank Dorothy Hodgkin Postgraduate Awards (DHPA) and Engineering and Physical Sciences Research Council (EPSRC) UK for funding.

- Thanks also to the other members of the HELIUM3D consortium. 


\section{HELUIM3D system}

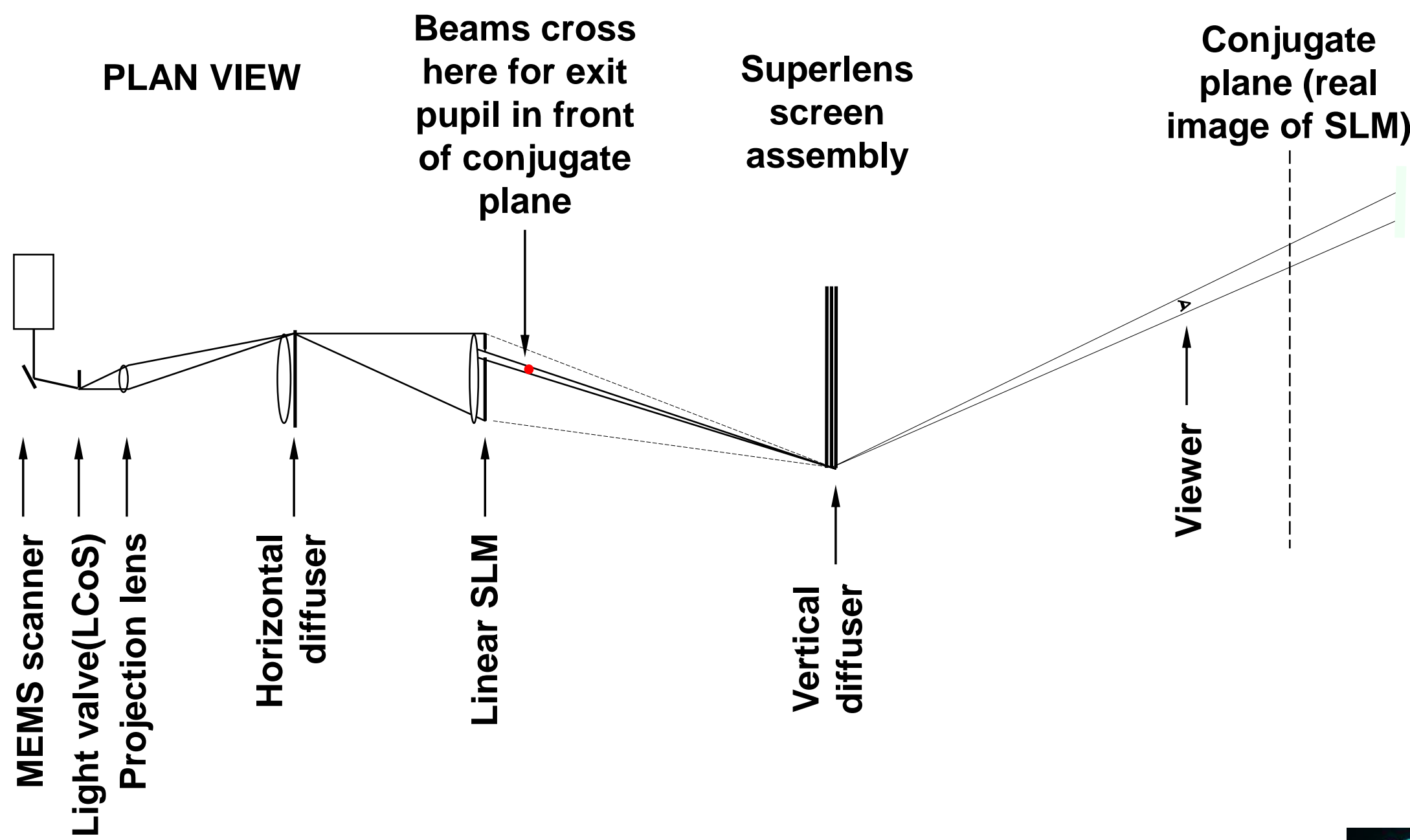




\section{Examples}

4 examples showing operation of time multiplexing of scanned views in different cases. 


\section{Example 1}

Single Aperture - Viewer at Conjugate plane

- $\quad$ SLM opening location corresponds to exit pupil location

- SLM opening location is stationary during a scan

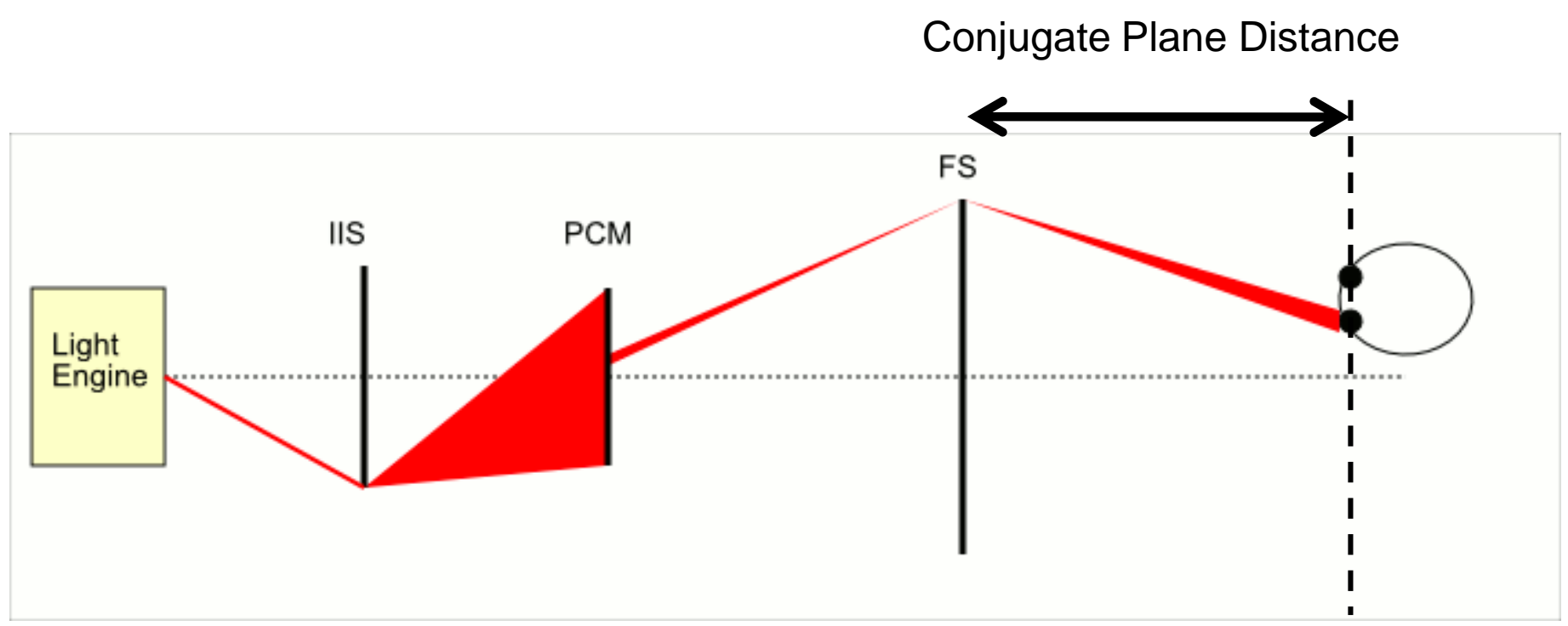




\section{Example 2}

Multiple Apertures - Viewers at Conjugate Plane

- SLM opening location is stationary during frame

- Multiple simultaneous apertures allow for more than one viewers

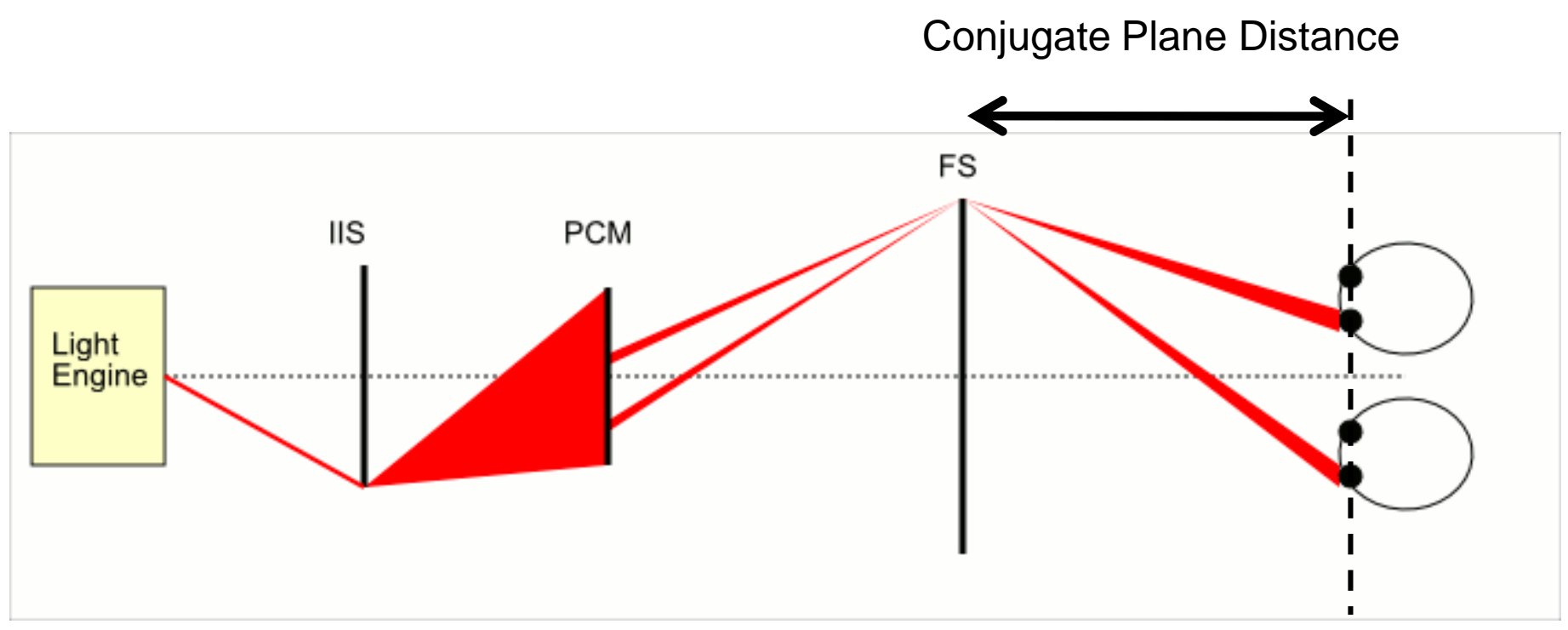




\section{Example 3}

Near-Field Operation

- SLM aperture moves during scan when viewer is not at conjugate plane

- Beam passes through a stationary 'virtual' point (green)

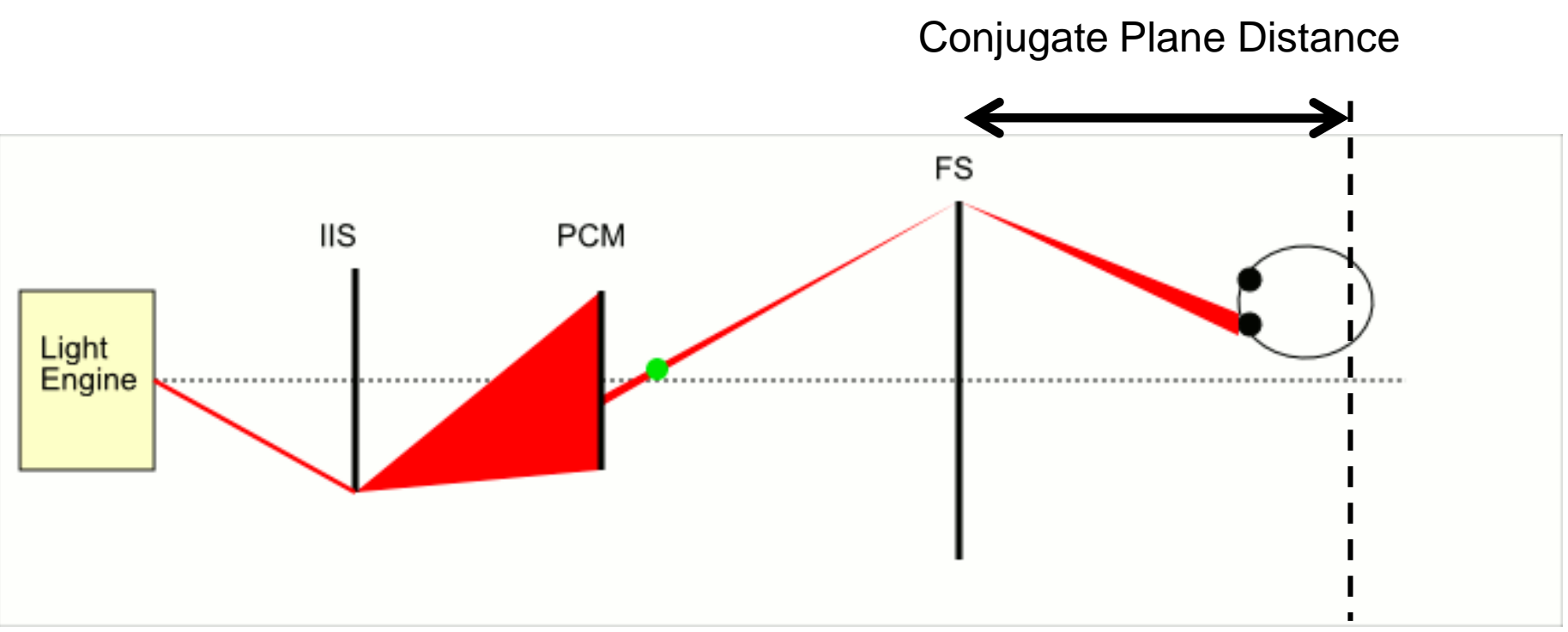




\section{Example 4}

Far-Field Operation

- SLM aperture moves during scan when viewer is not at conjugate plane

- Beam passes through a stationary 'virtual' point (green)

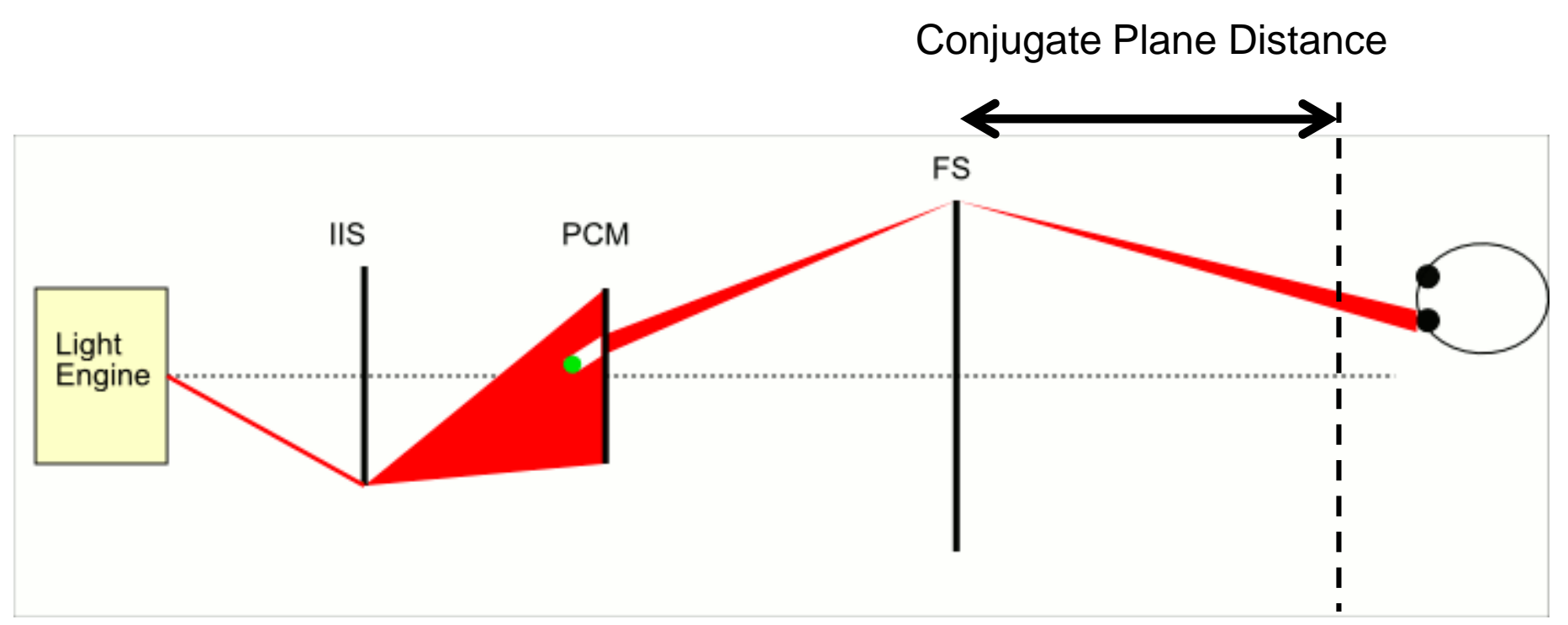

